\title{
Ageing and inpatient hospital expenditures: A study of steepening
}

\author{
Vahid Alipour ${ }^{1}$, Abolghasem Pourreza ${ }^{* 1}$, Majid Koosheshi ${ }^{2}$, Hassan Heydari ${ }^{3}$, Sara Emamgholipour \\ Sefiddashti ${ }^{1}$, Abbas Rahimi Foroushani ${ }^{4}$
}

\begin{abstract}
Background: Considering the health economics aspect, the effect of population aging on the growth of medical expenditures is of great importance. Thus, the aim of this study was to investigate the growth rate of inpatient hospital expenditures (IHE) of older age groups compared to younger age groups or testing of steepening hypothesis.

Methods: In this descriptive-analytic study, monthly IHE data of insured patients from April 2011 to March 2014 was collected from Iran Health Insurance Organization database. The sample consisted of 297,145 patients who were selected using stratified random sampling among the patients insured by different health insurance funds. Using the Age-cut method, patients were classified into two main age groups: older than 60 and under 60 years old. The average IHE of the two groups and the growth rate of their expenditures were estimated. At the $95 \%$ significance level, the difference in average growth rate of IHE was tested between the two age groups using tstatistic in Stata (version 13.0) software.

Results: The findings of this study revealed that per capita IHE for the older and younger groups was $\$ 469$ and $\$ 399$, respectively. The monthly average growth rate of IHE for the older (60-90 yrs.) and younger groups (30-59 yrs.) was $2.43 \%$ and $2.38 \%$, respectively. The difference between the monthly average growth rate of the older and younger groups was not statistically significant $(\mathrm{t}=-0.0332$; $P$ value $=0.9736$ )

Conclusion: Our study results rejected the steepening hypothesis. The monthly average growth rates of IHE in both older and younger age groups have risen to a similar extent over the period of 36 months. Further research should focus on the inpatient hospital expenditures of younger age groups to explain the causes of their increased expenditures.
\end{abstract}

Keywords: Ageing, Inpatient hospital expenditures, Steepening hypothesis

Copyright $\odot$ Iran University of Medical Sciences

Cite this article as: Alipour V, Pourreza A, Koosheshi M, Heydari H, Emamgholipour Sefiddashti S, Rahimi Foroushani A. Ageing and inpatient hospital expenditures: A study of steepening. Med J Islam Repub Iran. 2018 (11 Aug); 32:70. https://doi.org/10.14196/mjiri.32.70

\section{Introduction}

Over the past few decades, the effect of aging (people aged 60 years or over as a percentage of the total population) on health expenditures has changed and turned into a great concern among economists and health policymakers $(1,2)$. The aging population is rapidly increasing due to reduced fertility and mortality rate, the advancement of medical technology, and increased longevity. This has serious

Corresponding author: Dr Abolghasem Pourreza, abolghasemp@yahoo.com

1. Department of Health Management and Economics, School of Public Health, Tehran University of Medical Sciences, Tehran, Iran.

2. Department of Demography, Social Science Faculty, Tehran University, Tehran, Iran. 3. Department of Economic Sciences, School of Management and Economics, Tarbiat Modares University, Tehran, Iran.

4. Department of Epidemiology and Biostatistics, School of Public Health, Tehran University of Medical Sciences, Tehran, Iran. consequences, including increased chronic diseases, inability of different body organs to function properly, and increased long-term care. However, changes in the health of the aging population varies in different countries in a way that disability has declined among different aging groups in some countries and increased in some others. In general, chronic diseases and disabilities are prevalent among the aging population in all countries, so that disability and

$\uparrow$ What is "already known" in this topic:

There is no evidence about the growth of IHE for older age groups compared to other age groups or testing of steepening hypothesis in Iran. Previous studies have reported different results about the steepening hypothesis.

$\rightarrow$ What this article adds:

In this study, the steepening hypothesis, which states that medical expenditures of older age groups are growing faster compared to the rest of the population (younger age groups), was rejected. Based on our results, IHE of the younger age group (under $60 \mathrm{yrs}$.) has grown as much as that of the older age group (over 60 yrs.). 
chronic illness is one of the most important reasons for increasing disability-adjusted life-years (DALYs) among the elderly. The contribution of DALY in health problems of the aging population in developed countries is $33 \%$, it is $12 \%$ in developing countries, and $6 \%$ in less developed countries (3). The effect of aging on health expenditures is of great importance. Health conditions of the aging time period have led to an increase in per capita health care consumption and expenditure among the aging population compared to other age groups (4).

Based on evidence (5-7), people over the age of $60 \mathrm{im}-$ pose more health services and expenditures on the health systems and insurers than other age groups. In addition, some studies (8) indicate that the medical expenditures of the elderly people have grown faster than other age groups, which is referred to as the steepening hypothesis. This hypothesis is defined by Buchner et al. in three dimensions of time, age, and per capita health expenditures, which examines the per capita health expenditures in the elderly groups and other age groups over time (9). Gregersen et al. have identified that health expenditure growth in the elderly people has more than doubled compared to other age groups (10). Also, Felder et al., found that the growth rate of health expenditures remained steady in 40-70 age groups, but significantly increased in those 70 years and over. However, some studies have rejected the steepening hypothesis (11). In general, the results of studies on steepening depend on the type of common diseases between the older and other age groups as well as health transition stages.

Considering the factor of aging in Iran and increasing the aging population to more than 30 million in 2030 (12) as well as its effect on quantitative and qualitative dimensions of health services and medical expenditures, this study examined the steepening hypothesis using the data of hospitalization expenditures of the insured people covered by Iran Health Insurance Organization. From the perspective of the health economics, by testing the steepening hypothesis and estimating the growth rate of IHE for aging and other age groups, besides improving the scientific knowledge, adopting explicit policies to control and reduce medical expenditures arising from the changes in the demographic structure of Iran may be possible.

\section{Methods}

IHE data of insured patients from April 2011 to March 2014 were collected monthly from the patients' medical record database in Iran Health Insurance Organization. The studied sample consisted of 297,145 insured patients who were selected using stratified random sampling among the individuals covered by different funds in Tehran province. Data included the patient's insurance code, age, gender, and monthly IHE. IHE included reimbursement provided by Iran Health Insurance Organization expenditures to hospitals for the treatment of insured patients. Different age groups were classified into two age groups, 60-90 years and 30- 59 years, by Age-cut method; thus, the age of 60 years was considered as a cut-off point (9). Therefore, the younger age groups included 30-34, 35-39, 40-44, 45-49, $50-54$, and 55-59 years, and the older age groups included $60-64,65-69,70-74,75-79,80-84,85-89$, and +90 years old.

At first, the monthly average IHE of older and younger age groups, from April 2011 to March 2014 (36 months), were extracted. Then, the monthly growth rate of IHE for the two age groups was determined by the following formula:

$$
I H E_{l t}=\frac{\left[I H E_{i t}-I H E_{i(t-1)}\right]}{I H E_{i(t-1)}}
$$

Where; $I H E_{\imath t}$ is the growth rate of IHE for the age group $\mathrm{i}$ in month $\mathrm{t}, I H E_{i t}$ is the average IHE for the age group $\mathrm{i}$ in month $\mathrm{t}$, and $I H E_{i(t-1)}$ is the average IHE for age group $\mathrm{i}$ at month $\mathrm{t}-1$. Therefore, the growth rate was obtained for each month, except for the first month (growth rate was considered to be zero in April 2011). In the next step, the arithmetic mean of monthly growth rate of IHE for the two main age groups was calculated separately by the following formula:

$$
\text { Arithmetic mean of } I \dot{H} E_{l t}=\frac{1}{n} \sum_{i=1}^{n} I \dot{H} E_{l t}
$$

Where; $I H E_{l t}$ is the growth rate of the IHE for the age group $\mathrm{i}$ at the month $\mathrm{t}$, and $\mathrm{n}$ is the number of months $(\mathrm{n}=$ 36 months). Finally, at the $95 \%$ significance level, the average growth rate between the two age groups during 36 months was tested by t-statistics in Stata (version 13.0) software.

\section{Results}

Table 1 demonstrates that $42.9 \%(n=127,481)$ of the studied sample were in the older age group and $57.1 \%$ $(n=169,664)$ were in the younger age group. Moreover, $48.1 \%$ of those in the younger age group were male and $51.9 \%$ were female. In the older group, $50.3 \%$ were male and $49.7 \%$ were female.

In the first 12-months of the study period, the IHE for males and females in the younger group was $\$ 374.7$ and $\$ 256.8$, respectively, while the average expenditure for males and females in the older age group was \$391.7 and $\$ 345.8$, respectively. In general, the average IHE for males in both older and younger age groups had been more than females. However, in the age group of 90 years old, except for the second 12-months, females' expenditures surpassed those of males. More details related to the IHE are presented in Table 1.

Figure 1 demonstrates the average IHE based on age and sex from April 2011 to March 2014. The highest IHE rate in males belonged to 55-59 age group and the lowest to 3034 age group. In females' group, the IHE was the maximum in the +90 age group and it was the minimum in 30-34 age group. Findings showed that among females' group, the IHE of the elderly (over 80 years old) was increasing while it was decreasing among the males' group.

Table 2 demonstrates the monthly average growth rate of IHE from April 2011 to March 2014. The monthly average growth rate of IHE in younger patients (30-60 yrs.) was $2.38 \%$. In addition, the monthly growth rate of IHE in older 


\begin{tabular}{|c|c|c|c|c|c|c|c|c|c|}
\hline \multirow[t]{3}{*}{ Age group } & \multirow{2}{*}{\multicolumn{3}{|c|}{ Frequency }} & \multicolumn{6}{|c|}{ Per capita inpatient hospital expenditure (\$US) } \\
\hline & & & & \multicolumn{2}{|c|}{ First twelve-months } & \multicolumn{2}{|c|}{ Second twelve-months } & \multicolumn{2}{|c|}{ Third twelve-months } \\
\hline & $\begin{array}{l}\text { Number of in- } \\
\text { sured people }\end{array}$ & $\begin{array}{l}\text { Male } \\
(\%)\end{array}$ & $\begin{array}{c}\text { Female } \\
(\%)\end{array}$ & Male & Female & Male & Female & Male & Female \\
\hline Younger groups & $169664(57.1 \%)$ & 48.1 & 51.9 & 374.7 & 256.8 & 460.9 & 317.5 & 586.3 & 404.3 \\
\hline $30-34$ & $31388(10.6 \%)$ & 42.7 & 57.3 & 303.5 & 166.7 & 380.1 & 205.6 & 460.9 & 269.7 \\
\hline $35-39$ & $23431(7.9 \%)$ & 44.1 & 55.9 & 327.0 & 203.3 & 384.1 & 246.2 & 529.7 & 327.4 \\
\hline $40-44$ & $23626(8.0 \%)$ & 49.5 & 50.5 & 334.8 & 235.5 & 436.7 & 288.6 & 553.9 & 391.6 \\
\hline $45-49$ & $26220(8.8 \%)$ & 50.7 & 49.3 & 375.6 & 273.7 & 469.0 & 340.0 & 598.4 & 408.4 \\
\hline $50-54$ & $31681(10.7 \%)$ & 49.4 & 50.6 & 416.5 & 312.0 & 505.4 & 373.1 & 630.8 & 469.0 \\
\hline $55-59$ & $33318(11.2 \%)$ & 51.9 & 48.1 & 436.7 & 326.5 & 529.7 & 412.4 & 663.1 & 517.5 \\
\hline Elder groups & $127481(42.9 \%)$ & 50.3 & 49.7 & 391.7 & 345.8 & 485.2 & 428.6 & 610.5 & 537.8 \\
\hline $60-64$ & $30128(10.1 \%)$ & 51.5 & 48.5 & 428.6 & 353.6 & 525.6 & 440.7 & 659.1 & 537.8 \\
\hline $65-69$ & $26082(8.8 \%)$ & 49.4 & 50.6 & 416.5 & 357.6 & 509.5 & 436.7 & 634.8 & 541.8 \\
\hline $70-74$ & $23069(7.8 \%)$ & 49.8 & 50.2 & 392.3 & 347.0 & 477.1 & 432.6 & 598.4 & 541.8 \\
\hline $75-79$ & $23238(7.8 \%)$ & 52.5 & 47.5 & 367.9 & 330.6 & 460.9 & 412.4 & 586.3 & 537.8 \\
\hline $80-84$ & $15651(5.3 \%)$ & 49.1 & 50.9 & 342.0 & 336.6 & 420.5 & 404.3 & 553.9 & 505.4 \\
\hline $85-89$ & $8310(2.8 \%)$ & 46.4 & 53.6 & 358.5 & 338.9 & 452.9 & 420.5 & 582.2 & 582.2 \\
\hline+90 & $1003(0.3 \%)$ & 46.0 & 54.0 & 314.8 & 344.8 & 513.5 & 424.6 & 509.5 & 594.4 \\
\hline Total & $297145(100 \%)$ & 49.1 & 50.9 & - & - & - & - & - & - \\
\hline Cost ratio & - & - & - & 1.045 & 1.346 & 1.052 & 1.350 & 1.041 & 1.330 \\
\hline
\end{tabular}

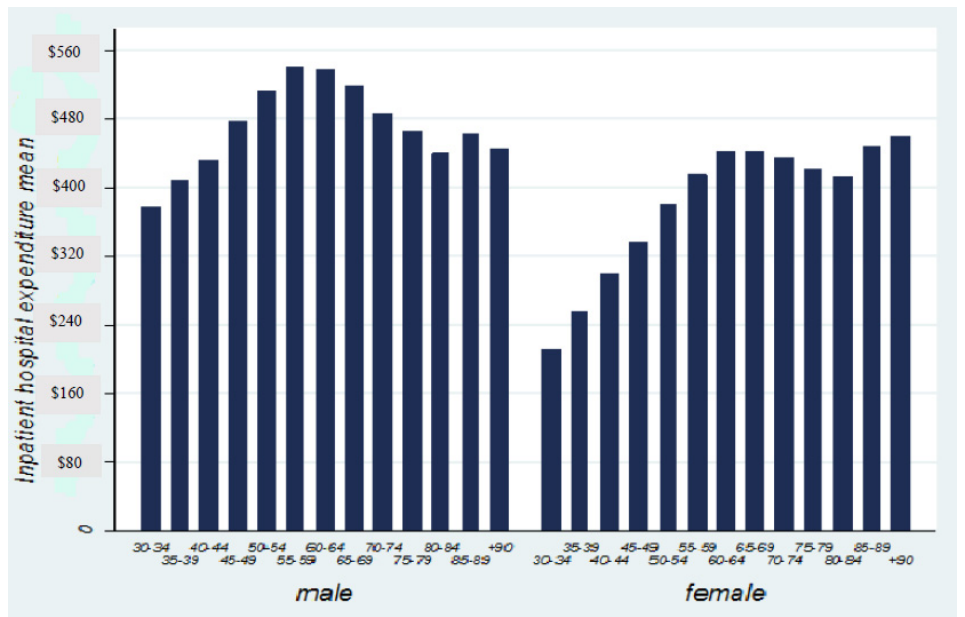

Fig. 1. Average inpatient hospital expenditure of age groups based on sex (\$US)

patients (60-90 yrs.) was $2.43 \%$. The highest growth rate was related to the age groups of 90 and 35-39, while the lowest growth rate of expenditures was related to 45-49 age group.

The $t$-statistic was used to test the statistical significance of the difference between the monthly average IHE growth rates of the two main age groups. According to Table 3, the null hypothesis, that is a statement of "no difference" in monthly average IHE growth rates of the two age groups at the level of $\mathrm{t}=-0.0332$, was rejected. Therefore, the monthly average growth rates of IHE in both older and younger age groups rose to a similar extent over the period of 36 months. The trend of growth rate of IHE in the two age groups is presented in Fig. 2.

\begin{tabular}{ccc} 
Table 2. Monthly average growth rate of inpatient hospital expenditure in different age groups \\
\hline Age groups & $\begin{array}{c}\text { Average inpatient } \\
\text { hospital expenditure (\$US) }\end{array}$ & $\begin{array}{c}\text { Monthly average growth rate } \\
(\%)\end{array}$ \\
\hline Younger groups & 399.0 & 2.38 \\
$30-34$ & 287.4 & 2.90 \\
$35-39$ & 328.7 & 3.03 \\
$40-44$ & 370.3 & 2.66 \\
$45-49$ & 412.4 & 2.09 \\
$50-54$ & 452.9 & 2.42 \\
$55-59$ & 485.2 & 2.28 \\
Older groups & 469.0 & 2.43 \\
$60-64$ & 497.3 & 2.77 \\
$65-69$ & 485.2 & 2.70 \\
$70-74$ & 465.0 & 2.41 \\
$75-79$ & 448.8 & 2.68 \\
$80-84$ & 432.6 & 2.10 \\
$85-89$ & 460.9 & 2.73 \\
+90 & 456.9 & 7.60 \\
\hline
\end{tabular}


Table 3. Comparison of the inpatient hospital expenditure growth rate of older and younger age groups using t test

\begin{tabular}{|c|c|c|c|c|c|c|}
\hline Variable & Observations & Mean & St. error & St. deviation & \multicolumn{2}{|c|}{$95 \%$ Conf. Interval } \\
\hline $30-59$ growth rate & 36 & .023875 & .0107203 & .0643217 & .0021117 & .0456383 \\
\hline $60-90$ growth rate & 36 & .024386 & .0110283 & .0661697 & .0019975 & .0467747 \\
\hline Combined & 72 & .024130 & .0076358 & .0647916 & .0089053 & .0393558 \\
\hline Difference & - & -.0005111 & .0153801 & - & -.0311858 & .0301635 \\
\hline
\end{tabular}

Diff $=$ mean $($ under 60$)-$ mean $($ above 60$)$

Ho: $\operatorname{diff}=0$

$\mathrm{t}=-0.0332$

Ha: $\operatorname{diff}>0$

$P$ value $=0.9736$

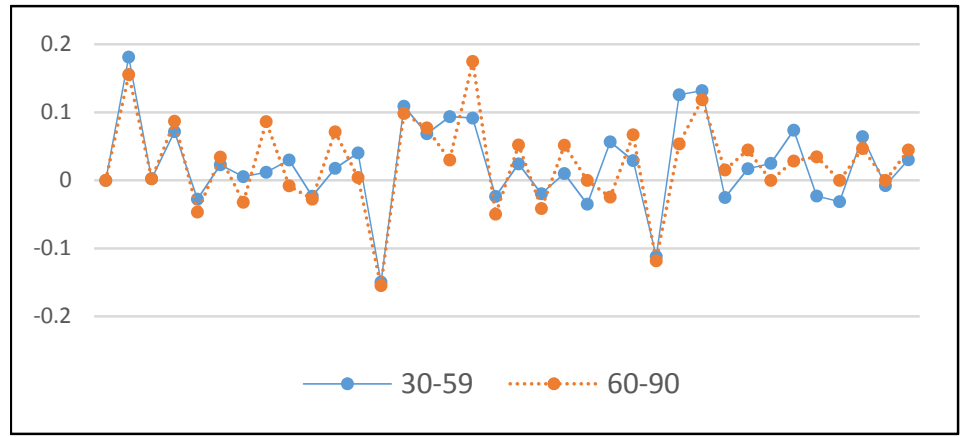

Fig. 2. The monthly growth of inpatient hospital expenditures for older (60-90 yrs.) and younger (30-59 yrs.) age groups

\section{Discussion}

The aim of this study was to test the steepening hypothesis or growth rate of IHE in older age groups in comparison with younger age groups. Cross sectional comparison (April, 2011 compared to March, 2014) of expenditures indicates that the IHE in the older age groups has not been higher than that of the younger age groups. In other words, the results showed that the difference in the average growth of IHE between older and younger age groups has not been statistically significant over the 36-month study period. Thus, the IHE growth rate of the two age groups has been the same. Previous results have shown that older people have more per capita health care spending than younger age groups (5, 13-16); and the reasons are high mortality, the epidemic of chronic disease, comorbidity, disabling conditions, and overall reduction in health states (17-19).

The results of this study support findings that show the growth rate of the elderly's health expenditures is slightly higher than other age groups (9). However, the difference between the average growth rates of these two age groups was not statistically significant. The results of the studies on the steepening hypothesis in different countries and various health care settings seem to vary. The evidence of a study from Norwegian hospitals showed that the growth rate of hospital expenditures in older patients is more than the other age groups and that the expenditure growth rate increased significantly, especially after the age of 70 (10). However, Felder and Werblow, in a study conducted on a sample of individuals under the coverage of Swiss health insurers and its 26 provinces, suggested that the steepening hypothesis is real but not to the extent that has previously been discussed (11). Furthermore, distribution of lifetime medical expenditures is in such a way that, in addition to older people, the near-birth ages also incur more health expenditures to the health systems (20). Therefore, based on the studies that have excluded near-birth health expenditures from the analysis, the expenditure growth was similar in the two age groups (over 60 and under 60 years old) and the steepening hypothesis was rejected (21). Some studies argued that the onset of diseases and disabilities will move to older age groups, which will lead to flattening of the age groups in the middle and a relatively steeper curve in other age groups, unless the peak is also moved (22). However, some studies argued that based on age-based rationing, the elderly were excluded from expensive medical treatment. In fact, these studies suggested that expensive and life-saving treatments are prioritized in the younger age groups, causing rapid growth of medical expenditures for younger age groups compared to the older $(23,24)$. However, this study had some limitations, and thus its results should be interpreted with caution. First, in this study, due to data limitation, merely the IHE was considered; while the major part of medical expenditures of the elderly is spent in outpatient and rehabilitation services and in informal home cares. Therefore, by taking into account the mentioned expenditures, the study results may change. Secondly, the IHE of under-30 age groups, who may have high hospital expenditures, were not included in this study. According to some studies $(25,26)$, the medical expenditures of under30 age groups, especially infants, can be significant and change the results.

\section{Conclusion}

According to the results of this study, the steepening hypothesis, that is, health care expenditures for older people are growing faster than for the rest of the population (younger people), was rejected. The high prevalence of expensive diseases and reducing the age of getting some diseases in the range of under 60 years old can lead to the increase of IHE. Based on the results, IHE of the younger age 
group (under 60 yrs.) has grown as much as that of the over 60 age group. This issue concerns the policymakers and health care managers. Further research should focus on the inpatient hospital expenditures of younger age groups that explain the causes of their increased expenditures.

\section{Acknowledgments}

This study was a part of $\mathrm{PhD}$ thesis, which has been supported by Tehran University of Medical Sciences (No.240/2014). The authors would like to thank all participants for their kind contributions to this project.

\section{Conflict of Interests}

The authors declare that they have no competing interests.

\section{References}

1. Meijer C, Wouterse B, Polder J, Koopmanschap M. The effect of population aging on health expenditure growth: a critical review. Eur J Age. 2013;10(4):353-61.

2. Wong A, van Baal PHM, Boshuizen HC, Polder JJ. Exploring the influence of proximity to death on disease-specific hospital expenditures: a carpaccio of red herrings. Health Econ. 2011;20(4):379-400.

3. United-Nations. World Population Ageing 2013. Department of Economic and Social Affairs, Population Division 2013.

4. Werblow A, Felder S, Zweifel P. Population ageing and health care expenditure: a school of 'red herrings'? Health Econ. 2007;16(10):1109-26.

5. Alemayehu B, Warner KE. The lifetime distribution of health care costs. Health Serv Res. 2004;39(3):627-42.

6. Meerding WJ, Polder J, Bonneux L, Koopmanschap M, van der Maas P. Health-care costs of ageing. The Lancet. 1998;351(9096):140.

7. Rezapour A, Azar FE, Aghdash SA, Tanoomand A, Shokouh SMH, Yousefzadeh N, et al. Measuring equity in household's health care payments (Tehran-Iran 2013): technical points for health policy decision makers. Med J Islam Repub Iran. 2015;29:246.

8. Bjorner TB, Arnberg S. Terminal costs, improved life expectancy and future public health expenditure. Int $\mathrm{J}$ Health Care Fin Econ. 2012;12(2):129-43.

9. Buchner F, Wasem J. "Steeping" of Health Expenditure Profiles. The Geneva Papers on Risk and Insurance Issues and Practice. 2006;31(4):581-99.

10. Gregersen FA. The impact of ageing on health care expenditures: a study of steepening. Eur J Health Econ. 2014;15(9):979-89.

11. Felder S, Werblow A. Does the Age Profile of Health Care Expenditure Really Steepen over Time? New Evidence from Swiss Cantons. The Geneva Papers on Risk and Insurance Issues and Practice. 2008;33(4):710-27.

12. United-Nations. World population prospects. The 2012 revision. New York: UN. 2012.

13. Seshamani M, Gray A. Ageing and health-care expenditure: the red herring argument revisited. Health Econ. 2004;13(4):303-14.

14. Morgan S, Cunningham C. Population aging and the determinants of healthcare expenditures: the case of hospital, medical and pharmaceutical care in british columbia, 1996 to 2006. Healthcare Policy. 2011;7(1):68.

15. Caley M, Sidhu K. Estimating the future healthcare costs of an aging population in the UK: expansion of morbidity and the need for preventative care. J Pub Health. 2010;33(1):117-22.

16. Azar FE, Asiabar AS. Does leadership effectiveness correlates with leadership styles in healthcare executives of Iran University of Medical Sciences. Med J Islam Repub Iran. 2015;29:166.

17. Raitano M. The impact of death-related costs on health care expenditure: a survey. 2006.

18. Payne G, Laporte A, Deber R, Coyte PC. Counting Backward to Health Care's Future: Using Time-to-Death Modeling to Identify Changes in End-of-Life Morbidity and the Impact of Aging on Health Care Expenditures. Milbank Quart. 2007;85(2):213-57.

19. Sajjadi HS, Seyedin H, Aryankhesal A, Asiabar AS. A systematic review on the effectiveness of thermography in diagnosis of diseases. Int J ImagiSyst Technol. 2013;23(2):188-93.

20. Pourreza A, Alipour V, Arabloo J, Bayati M, Ahadinezhad B. Health production and determinants of health systems performance in WHO Eastern Mediterranean Region. East Mediterr Health J. 2017;23(5):368.

21. Melberg HO. Are healthcare expenditures increasing faster for the elderly than the rest of the population? Expert Rev Pharmacoecon Outcomes Res. 2014;14(5):581-3.

22. Fries JF. Aging, natural death, and the compression of morbidity. Bull. World Health Organ. 2002;80(3):245-50.

23. Zweifel P. Rationing of health care: is there an economic rationality to it? Eur J Health Econ. 2015;16(8):797-800.

24. Vasquez L. Access to Health Care Coverage in the United States: Rationing People Rather than Services. Reflect Healthcare Manag. 2017;1(1):11.

25. Cutler DM, Meara E. The medical costs of the young and old: a fortyyear perspective. Frontiers in the Economics of Aging: University of Chicago Press; 1998. p. 215-46.

26. Hartwig J. What drives health care expenditure?-Baumol's model of ‘unbalanced growth’revisited. J Health Econ. 2008;27(3):603-23. 